\title{
À la recherche d'une culture scolaire
}

\section{Dominique Borne}

\section{(2) OpenEdition}

\section{Journals}

Édition électronique

URL : http://journals.openedition.org/ries/3413

DOI : 10.4000/ries.3413

ISSN : 2261-4265

\section{Éditeur}

Centre international d'études pédagogiques

\section{Édition imprimée}

Date de publication : 1 décembre 1996

Pagination : 27-29

ISSN : 1254-4590

\section{Référence électronique}

Dominique Borne, «À la recherche d'une culture scolaire », Revue internationale d'éducation de Sèvres

[En ligne], 12 | 1996, mis en ligne le 27 août 2013, consulté le 22 septembre 2020. URL : http:// journals.openedition.org/ries/3413; DOI : https://doi.org/10.4000/ries.3413 


\section{programmes et politiques
Introduction}

\section{A la recherche d'une culture scolaire}

\section{Dominique Borne}

Les articles rassemblés ici dessinent une évidence. Les programmes, sous des formes certes différentes, sont bien " au centre " des politiques éducatives en Europe. Leur définition entraîne de vastes débats nationaux, comme si les années 1990 marquaient une évolution de la réflexion sur l'éducation. Seraiton passé des réformes de structure (cycles, filières) à des réformes mettant en cause les contenus et donc les finalités et les objectifs de l'école?

Les contenus des programmes ne posaient guère de problème quand l'enseignement secondaire était réservé à quelques-uns; la culture transmise était naturellement celle des élites sociales. L'enseignement de masse impose de définir une "culture scolaire ", d'autant plus nécessaire que l'école subit désormais la concurrence de flux culturels qui ne sont ni hiérarchisés ni contrôlés et qui obéissent à une pure logique marchande. La rapidité des transformations économiques et sociales qui affectent l'Europe n'est pas non plus étrangère à cette nouvelle priorité : mieux définir les objectifs et les finalités de l'école afin d'affermir le pacte social et de réaffirmer un consensus autour de l'identité nationale. C'est-à-dire que, sans toujours en avoir l'air, les questions débattues ici sont politiques et civiques.

L'organisation de vastes consultations sur les objectifs et les contenus des programmes va dans le même sens. Les gouvernements, pour obtenir un très large consensus, étendent le processus de réforme sur plusieurs années. Des premières "directions provisoires", en 1991, à l'entrée en vigueur des programmes prévue pour 1998, le Land de Thuringe reconstruit ainsi les programmes sur la longue durée en multipliant consultations et évaluations. La réforme britannique de 1988 n'est pas encore stabilisée en 1996. Les consultations ne se limitent pas aux «experts». Les professeurs sont dorénavant partie prenante. Cependant les parents et les autorités locales sont inégalement présents. En France les parents figurent, par le biais des associations de parents d'élèves, parmi les groupes consultés, mais leur rôle reste formel. Au Danemark, les conseils d'administration de chaque établissement, présidés par un parent d'élève, élaborent les programmes qui «peuvent s'écarter des directives ministérielles ou les suivre »; ces propositions doivent être ensuite approuvées par les municipalités.

Les différentes voies de la recherche du consensus renvoient à des modèles nationaux. Les programmes, dit Alain Boissinot, directeur des Lycées et Collèges, sont « la charte commune de tous les Français, la dimension nationale du projet éducatif ». Les autorités locales et régionales qui construisent et entretiennent pourtant les établissements scolaires n'ont aucune autorité sur les 
contenus de l'enseignement. Il est vrai qu'en France les programmes nationaux sont le symbole de l'école républicaine et laïque qui, au delà des diversités, dispense à tous l'égalité d'éducation. La laïcité à la française impose à l'enseignant de ne choquer aucun père de famille - l'école respecte les croyances des personnes - mais seule la République peut définir des programmes qui sont destinés à former les futurs citoyens.

Ainsi, malgré des préoccupations communes, les réformes, comme les débats qu'elles provoquent, sont encore marquées par l'histoire et les traditions éducatives de chaque État. Le débat britannique est en ce sens éclairant. L'Education Reform Act de 1988 propose des programmes nationaux obligatoires alors que depuis 1944 la seule matière imposée à tous les établissements était l'éducation religieuse. Le débat " aborde les questions fondamentales d'identité nationale... ». Il est vécu par les enseignants comme une tentative de restauration des valeurs. Le programme national voudrait imposer l'enseignement de la grammaire, des grandes œuvres littéraires, des dates et des figures du glorieux passé britannique. Les opposants insistent au contraire sur l'acquisition de compétences et de méthodes et l'apprentissage par les élèves de la créativité. Enfin n'est-ce pas le passé récent qui explique qu'en Thuringe, nouveau Land allemand, la réforme insiste sur le travail libre et créatif des élèves ?

Il ne faudrait pas cependant exagérer l'opposition entre programmes nationaux obligatoires et programmes d'initiative locale. Les États définissent tous des objectifs généraux et, même dans les systèmes qui restent centralisés, comme en France, l'autonomie des établissements a toujours sa place. La définition nationale des programmes exprime le refus d'une dissolution de l'école dans la société, mais elle ne doit pas être une restauration. Les élèves ont changé; leur hétérogénéité explique la nécessaire liberté pédagogique des enseignants. Les programmes par ailleurs ne doivent pas saturer le temps scolaire.

Les textes rassemblés ne permettent pas de comparer les savoirs définis par les programmes. Les réformes se contentent de préciser les compétences, générales ou spécifiques à chaque discipline, attendues des élèves à la fin d'un cycle. L'Espagne classe les contenus sous trois rubriques: "faits et concepts », "méthodes", "comportements, valeurs et règles ». Le débat entre ceux qui prônent l'acquisition d'outils permettant d' " apprendre à apprendre " et ceux qui insistent sur les savoirs disciplinaires apparait de biais. Les textes danois placent l'élève "au cœur de l'enseignement " et incitent les enseignants à s'appuyer sur son expérience concrète. L'insistance des réformateurs à promouvoir la trandisciplinarité et les thèmes transversaux comme un moyen de contourner l'enfermement disciplinaire et pour donner cohérence à l'ensemble d'une formation est également significative. Le monde change: comment répondre aux nouveaux besoins sociaux et culturels à partir de disciplines enracinées dans leurs traditions? 
Autrement dit, les programmes ne peuvent plus être définis comme un héritage culturel transmis de génération en génération. Les élèves ont des besoins spécifiques nouveaux: ils doivent être préparés à l'exercice de la citoyenneté; les valeurs de la démocratie sont toujours présentes dans les réformes. Ils doivent aussi apprendre que la nature doit être ménagée et protégée. C'est la "touche verte" qui, pour les Danois, doit colorer les programmes de chaque discipline.

Ce dossier peut-il répondre à toutes les questions? Les incertitudes qu'il révèle sont significatives des interrogations actuelles. Insister sur les compétences n'est-ce pas risquer d'évacuer une réflexion de fond sur les contenus d'une culture scolaire encore bien problématique? Il est vrai que le mot "compétences" est si polysémique que son emploi, tout au moins en France, pose problème. Les résistances opposées par les enseignants aux réformes sont évoquées ici ou là. Certains pays ont mis en place, comme en Espagne, des plans ambitieux de formation continue. Il semble que, parfois, les prescriptions didactiques et pédagogiques soient plus rigides que la définition des savoirs eux-mêmes et ceci à l'inverse de la pratique française. Comment faire pour que les objectifs ambitieux des réformes se traduisent par un changement réel dans les classes? Ces objectifs ne sont-ils pas, dans la pratique, abandonnés à l'interprétation des rédacteurs de manuels ? Comment évaluer les effets d'une réforme? Se posent enfin tous les problèmes de la formation des enseignants. Comment briser l'individualisme et inciter au travail en équipe ? Préparer un enseignant à son métier ce n'est pas seulement lui faire assimiler les savoirs d'un champ scientifique donné ou d'un programme nécessairement éphémère. Mais enseigner ce n'est pas non plus une simple pratique; réduire l'enseignement à une technologie éducative c'est tomber dans ce "puits méthodologique » évoqué par Alain Bouvier.

Aucune réforme ne peut, de l'extérieur, faire naître cette alchimie singulière de la classe où tout se noue. La réforme précise objectifs et contenus des programmes, mais seul l'enseignant peut leur donner sens. Pour cela il faut qu'il soit maitre de la place et des démarches spécifiques de la discipline qu'il enseigne, cela pourrait s'appeler l'épistémologie. Mais il faut aussi que son attention à ses élèves leur donne les moyens de s'approprier une culture. 